\title{
Análise Estratégica sob Ótica Relacional: Enfocando Grupos e Blocos Estratégicos
}

\author{
Irene Raguenet Troccoli \\ T. Diana L. v. A. Macedo-Soares
}

\section{Resumo}

Este artigo apresenta os resultados de pesquisa primária que buscou analisar o impacto das alianças e redes estratégicas na conduta e no desempenho de empresas situadas em um grupo estratégico entendido como conjunto de empresas que competem mais acirradamente entre si por terem compromissos semelhantes de escopos e recursos. Esta análise relacional foi realizada no âmbito de um estudo de casos múltiplos, em um setor do agronegócio brasileiro, com o auxílio do conceito de bloco estratégico - empresas estruturalmente semelhantes e mais densamente conectadas do que as demais na indústria, constituindo, assim, uma rede. Aplicaram-se indicadores pertinentes a estrutura, modalidade e composição de redes ao caso de empresas que constituíam, na indústria de suco de laranja, simultaneamente grupo e bloco estratégico. Os resultados mostraram que a análise relacional de grupos estratégicos complementa a análise tradicional - posicionamento ou resource-based - das implicações estratégicas de fatores organizacionais e macro-ambientais específicos às empresas do grupo. Também mostraram que as redes capacitam a empresa situada em um grupo estratégico a ultrapassar as barreiras intergrupais, na medida em que complementam capacidades, provêem acesso a informações relevantes, proporcionam economias de escala e ajudam a gerenciar riscos e incertezas.

Palavras-chaves: grupos estratégicos; blocos estratégicos; redes; alianças; suco de laranja.

\section{Abstract}

This paper presents the main results of primary research that aimed at analyzing the impact of strategic alliances and networks on the conduct and performance of firms in strategic groups - set of firms that compete more fiercely among each other because they have similar scope and resource commitments. This relational analysis was part of a multiple case study in a Brazilian agribusiness sector, conducted with the help of the strategic block concept - set of firms that are connected more densely to each other than to other firms in the industry, forming thus a network. Indicators pertinent to the structure, modality and composition of strategic networks were applied to the case of firms in the orange juice industry that constituted, simultaneously, strategic group and block. Research results confirmed that relational analysis of strategic groups complements traditional analysis (e.g. positioning or resource-based view) - of strategic implications of organizational, structural and macro environmental factors specific to firms in the group. The results also strongly suggested that networks enable a firm of a strategic group to overcome inter-grupal barriers, inasmuch as that they complement capabilities, provide access to relevant information, contribute to scale economies and help manage risks and uncertainty.

Key words: strategic groups; strategic blocks; networks; alliances; orange juice. 


\section{INTRODUÇÃO}

Até os anos 80, as empresas foram dominadas pelo conceito da rivalidade, em consonância com as condições que então imperavam - produção em massa, existência de mercados oligopólicos, baixa competição estrangeira. Porém, no final daquela década, o mundo passou por uma mudança radical associada à globalização. A economia começou a se caracterizar por uma maior liberalização dos mercados e os consumidores aumentavam suas exigências, requerendo soluções cuja complexidade implicava, freqüentemente, a integração de recursos de várias empresas. Simultaneamente, a competição se intensificava.

Neste contexto, as empresas viram-se impelidas a experimentar novas configurações organizacionais, desenvolvendo funções situadas fora dos seus limites tradicionais; buscaram estabelecer não simplesmente alianças estratégicas bilaterais, mas alianças multilaterais, configurando redes estratégicas, com vistas a sustentar sua vantagem competitiva.

Pela mesma razão, as redes estratégicas começaram a ser investigadas de modo crescente na área de gestão estratégica. A principal preocupação tem sido com os motivos para estabelecer alianças e redes. Apenas, recentemente, as suas implicações estratégicas foram objeto de estudos (Galaskiewics e Zaheer, 1999, Gulati, Nohria e Zaheer, 2000). Destes estudos, poucos têm focado os grupos estratégicos (Nohria e Garcia-Pont, 1991).

Este artigo compartilha os resultados de pesquisa primária que buscou contribuir a estas recentes investigações, ao analisar o impacto das alianças e redes estratégicas na conduta e no desempenho de empresas situadas em grupo estratégico - GE, ou seja, um grupo de empresas que competem mais acirradamente entre si do que com as demais na indústria.

Para atingir o objetivo da pesquisa de evidenciar a importância de levar em conta as implicações de alianças e redes na condução de análises estratégicas de empresas em GEs, um estudo de casos múltiplos foi realizado, enfocando empresas na indústria brasileira de suco de laranja pronto para beber industrializado, que poderiam ser consideradas como constituindo, simultaneamente, um GE e um bloco estratégico - BE, ou seja, empresas mais densamente conectadas entre si, formando assim uma rede estratégica.

O artigo foi estruturado em seis partes. Na primeira, explicam-se as definições adotadas para os conceitos-chaves. Na segunda, propõem-se dimensões 
pertinentes à análise relacional no caso de empresas em GEs. Na terceira parte, descreve-se sucintamente a metodologia da pesquisa e, na quarta, são apresentados seus principais resultados. Na quinta, estes são discutidos à luz da questão das barreiras de mobilidade dos GEs. Na última parte, resumem-se os subsídios relevantes da pesquisa, tanto para administradores quanto para pesquisadores.

\section{Conceitos-chaves}

A definição para o conceito central de grupo estratégico - GE foi inspirada em Cool e Schendel (1987): um grupo de empresas que competem mais acirradamente entre si em uma determinada indústria, por adotarem combinações semelhantes de compromissos de escopo e de recursos, de modo independente ou não. Ou seja, não se entende que a identificação de GEs implique necessariamente análise de clusters. O conceito surgiu no final dos anos de 1970, com o objetivo de auxiliar a análise das diferenças na lucratividade entre as empresas no mesmo setor industrial, ao representar um nível intermediário de análise entre a empresa e a indústria como um todo (Fiegenbaum e Thomas, 1993). Depois de grande apelo inicial, revelou certas limitações. Por exemplo, tem-se questionado até que ponto os GEs realmente existem ou se são apenas artefatos de métodos de cálculo de clusters (Cool e Schendel, 1987). Na pesquisa, em acordo com Barney (1998), argumentou-se que, apesar das críticas feitas ao construto GE, este pode ser muito útil na caracterização da estrutura das ameaças e oportunidades pertinentes à atuação estratégica das empresas em determinada indústria.

No caso do conceito de bloco estratégico - BE, referiu-se o construto de Nohria e Garcia-Pont (1991): um conjunto de empresas em uma indústria que são estruturalmente similares e que se conectam mais densamente entre si do que com as demais, para ganharem capacitações passíveis de levar a uma posição competitiva mais vantajosa e, com isto, diminuírem a incerteza competitiva. Constitui forma particular de rede estratégica, uma visão alternativa na análise dos GEs, cujos benefícios são evidentes, quando o ambiente do GE é caracterizado por alianças estratégicas, tendo em vista sua capacidade de tornar mais inteligível a maior complexidade envolvida. Na pesquisa em exame neste artigo, propôs-se uma extensão ao conceito original de $\mathrm{BE}$, isto é, que em uma indústria composta por mais de um setor, se possa ter, em um destes setores, um bloco identificado por conexões entre as empresas, que se originem de suas atuações em outro setor.

Inspirando-se fortemente em Caves e Porter (1977), barreiras de mobilidade foram definidas como fatores - atributos estruturais do GE, tais como economia 
de escala, acesso a canais de distribuição e outros recursos distintivos - que dissuadem, por tornarem difíceis e onerosos os movimentos de empresas de uma posição estratégica para outra. Trata-se de uma extensão, ao nível dos GEs, do conceito de barreiras de entrada na indústria. Note-se que, na pesquisa, de acordo com a definição de GE adotada, as barreiras de mobilidade foram atribuídas aos compromissos de escopo e de recursos das empresas nos grupos estratégicos.

Para o conceito-chave de rede estratégica, adotou-se a definição de Gulati et al. (2000):

"um conjunto de relacionamentos da empresa, tanto horizontais como verticais, com outras organizações - fornecedores, clientes, concorrentes e outras entidades - incluindo relações que atravessam as fronteiras de indústrias e países. São compostas de laços interorganizacionais duradouros, de significado estratégico, e incluem alianças entre empresas e demais entidades".

Alianças estratégicas foram definidas de forma ampla, inspirando-se também em Gulati (1998, p. 293), como “arranjos voluntários entre empresas, envolvendo troca, compartilhamento, ou co-desenvolvimento de produtos, tecnologias ou serviços", que contribuem diretamente para a vantagem competitiva da empresa. Baseando-se em Nohria e Garcia-Pont (1991), foram classificadas de acordo com seus graus de intensidade: fusões e aquisições, joint ventures, franquias, licenciamentos e acordos.

Para apreciar melhor os resultados apresentados, definem-se a seguir dois termos específicos ao setor sob estudo: a) suco de laranja concentrado congelado SLCC, é o suco do qual se extraiu água até chegar-se à concentração de $65^{\circ}$ Brix (65\% de sólidos solúveis e 35\% de água), forma ideal ao congelamento tanto para o transporte em grandes distâncias quanto para o armazenamento a frio; b) suco de laranja pronto para beber industrializado - SPBI, em embalagem da Tetra Pak, considerado na pesquisa apenas em duas formas: (1) o suco integral puro; (2) o suco de laranja concentrado reconstituído e com a adição de até $40 \%$ de açúcar.

\section{Dimensões e Indicadores Pertinentes à Análise Relacional no CAso de Empresas em GES}

Conforme observado por Galaskiewicz e Zaheer (1999), as redes estão constantemente em evolução; assim, quando empresas atuam em redes, sua 
habilidade de influenciar este processo de mudança torna-se crítica para seu sucesso estratégico. Baseando-se na literatura sobre redes sociais, estes autores identificaram três dimensões da rede cujas características puderam influenciar a conduta e o desempenho de empresas em redes: (1) Estrutura. Padrão de relacionamentos, cujas implicações dependem da sua coesão, em termos de ter laços diretos, indiretos, ou estruturalmente equivalentes (compartilhamento dos mesmos clientes ou mesmos tipos de laços), da centralidade/posição da empresa na rede (participação em número significativo de relacionamentos), e da existência de orifícios estruturais (structural holes), quando os parceiros estão conectados apenas por meio da empresa focal que pode explorar essa situação (por exemplo, corretora de seguros). (2) Composição. Membros da rede, cujas implicações dependem da sua riqueza em recursos dos quais a empresa necessita. (3) Modalidades. O tipo de regras/normas institucionais que governam o comportamento relacional da rede, contratos formais ou acordos informais, cujas implicações variam de acordo com o tipo de laço colaborativo ou oportunístico.

Gulati et al. (2000) contribuíram de forma significativa à pesquisa de construtos relacionais. Fundamentando-se em investigações empíricas de outros pesquisadores, acrescentaram características pertinentes às três dimensõeschaves: a densidade - estrutura da rede; o status - composição; os graus forte/ fraco e múltiplo/simples - modalidade. Também mostraram como estes fatores podem ter implicações nos níveis da indústria e do GE, referindo-se a elas, explicitamente, em termos de oportunidades e limitantes (ameaças). Argumentavam que, enquanto o acesso potencialmente mais fácil aos recursos valiosos dos membros da rede constituía uma oportunidade evidente, o aspecto lock-in (ibid, p. 203) de certos tipos de relacionamentos da rede criavam uma ameaça, pois impedia estabelecer alianças com outras empresas mais produtivas.

No caso de empresas de GEs que atuam em redes, tais como blocos estratégicos, a identificação destas implicações é importante, já que o sucesso da empresa depende, em grande parte, da sua capacidade de administrar as ameaças e explorar as oportunidades que se apresentam ao GE (Barney, 1996).

Conseqüentemente, o conceito de rede convida a que a análise da conduta e do desempenho de empresas em GEs transcenda o paradigma tradicional voltado para a estrutura da indústria, como no caso da escola posicionamento (Porter, 1980), ou o da visão baseada em recursos (Wermerfelt, 1984), que enfatiza a mobilização de recursos distintivos. Pela mesma ocasião, implica uma releitura do conceito de barreiras de mobilidade enquanto construto-chave ao entendimento do desempenho de empresas em GEs: se as alianças e redes visam a eliminar as dificuldades estruturais de acesso a recursos-chaves, ipso facto podem contribuir 
para melhorar as condições sob as quais poderia ocorrer a entrada de uma empresa em um GE ou a migração de uma empresa de um grupo para outro.

Com vistas a capturar e analisar os dados relacionais relativos aos GEs, estabeleceu-se, com base na revisão da literatura, uma lista de referência de construtos pertinentes às implicações estratégicas da rede no caso de empresas em GEs, apresentada no Quadro 1 de forma resumida, com os indicadores para implicações positivas (oportunidades) em negrito.

\section{Quadro 1: Dimensões e Indicadores Pertinentes à Análise Relacional de GEs}

\begin{tabular}{|l|l|l|}
\hline \multicolumn{1}{|c|}{ Dimensões } & \multicolumn{1}{|c|}{ Características - construtos } & \multicolumn{1}{c|}{$\begin{array}{c}\text { Indicadores das } \\
\text { Oportunidades / Ameaças }\end{array}$} \\
\hline Estrutura da rede do GE & $\begin{array}{l}\text { Densidade da Rede } \\
\text { 1.2 Posição na Rede } \\
1.3 \text { Orifícios Estruturais }\end{array}$ & $\begin{array}{l}\text { Alta / Baixa } \\
\text { Central/Periférica } \\
\text { Existência / Não Existência }\end{array}$ \\
\hline Composição da rede do GE & $\begin{array}{c}\text { 2.1 Identidade da indústria do } \\
\text { GE } \\
\text { 2.2 Status da indústria do GE } \\
\text { 2.3 Acesso a Recursos da } \\
\text { indústria do GE } \\
\text { 2.4 Identidade/Status de parceiros } \\
\text { do GE }\end{array}$ & $\begin{array}{l}\text { Forte / Fraca } \\
\text { Sucesso / Fracasso } \\
\text { Difícil / Fácil } \\
\text { Forte / Fraca } \\
\text { Sucesso / Fracasso }\end{array}$ \\
& $\begin{array}{c}\text { 2.5 Acesso a Recursos de } \\
\text { parceiros do GE }\end{array}$ & Difícil / Fácil \\
\hline $\begin{array}{c}\text { Modalidades / Tipo de laço } \\
\text { das empresas do GE que } \\
\text { atuam em redes }\end{array}$ & $\begin{array}{c}\text { 3.1 Força das conexões } \\
\text { 3.2 Natureza dos laços dentro do do } \\
\text { GE e através das indústrias } \\
\text { cliente e fornecedora }\end{array}$ & $\begin{array}{l}\text { Forte / Fraca - Favorece / Não } \\
\text { Favorece Coordenação } \\
\text { Oligopolística } \\
\text { Colaborativa / Oportunista } \\
\text { Benigna / rivalidade }\end{array}$ \\
\hline
\end{tabular}

\section{Metodologia}

\section{Universo Pesquisado}

A escolha do setor brasileiro do SPBI para a realização da pesquisa deveu-se a dois motivos. O primeiro foi o crescimento da sua importância dentro do agronegócio citrícola brasileiro. As estatísticas sugerem que o consumo interno do SPBI já seria da ordem de 108 milhões de litros (Troccoli, 2002). O segundo motivo foi que o setor SPBI oferecia um caso especial de GE que era, ao mesmo tempo, BE. Esta coincidência foi particularmente útil para a realização da pesquisa, já que envolveu confrontação de implicações estratégicas identificadas, 
respectivamente, pelas análises relacional e tradicional, dado que o conceito de $\mathrm{BE}$ se enquadra simultaneamente nas teorias de GE e de redes de relacionamento. Ou seja, permitiu maior controle das variáveis pertinentes à análise do impacto das redes no GE.

Também se adotaram três outras delimitações na pesquisa de campo: (1) foco apenas nos produtores de SPBI no Estado de São Paulo, onde se concentrava $90 \%$ da produção comercial de laranja no país; (2) delimitação temporal a fins de 2001 - início de 2002, quando duas empresas no mercado nacional de SPBI - Citrovita e Cargill Citrus - formavam simultaneamente GE e BE; (3) delimitação às 4 empresas - Citrovita, Cargill Citrus, Hildebrand e Guacho Agropecuária - que realizavam o esmagamento da laranja em base constante e que se destacavam pelo número de parcerias com lacticinistas ou supermercados.

\section{Métodos de Pesquisa}

Foram realizadas duas pesquisas, sendo uma secundária e uma primária. A pesquisa secundária caracterizou-se como bibliográfica na área de GEs e BEs, bem como documental e telematizada no âmbito do estudo de multicasos. Revelouse insumo primordial na realização da pesquisa primária, porquanto possibilitou a aplicação dos construtos para a análise dos GEs pela perspectiva relacional, assim como a identificação das barreiras de mobilidade no sub-setor do SPBI (Troccoli e Macedo-Soares, no prelo).

Como se examinou um caso-limite referente a um universo composto de apenas quatro empresas, dentre as quais se encontrava um GE que também era um BE, na pesquisa primária justificou-se a adoção de um estudo de multicasos, ao invés da análise tradicional de clusters, que teria requerido número estatisticamente significativo de empresas. Aliás, esta escolha era coerente com a definição de GE, porquanto não se entendia que sua identificação implicava necessariamente análise de clusters. Ademais, a coincidência entre universo e amostra capacitou o estudo de casos múltiplos a prover generalizações ao universo todo investigado.

A pesquisa primária foi realizada durante a segunda metade de 2002. De acordo com a metodologia de Yin (1994) adotada, utilizou-se triangulação de métodos para conseguirem-se dados de múltiplas fontes que permitissem assegurar conclusões mais aderentes à realidade, realizando-se levantamento sobre as percepções de executivos com poder decisório no negócio do SPBI nas quatro empresas escolhidas. Para tanto, desenvolveu-se um questionário 
predominantemente estruturado, inspirando-se em dois instrumentos já testados: de Soekarsono (2001) para questões relativas às estratégias das empresas em GEs, e de Tauhata (2002) para as questões pertinentes às implicações das suas redes, ou seja dos BEs. O questionário incluía perguntas a serem respondidas de quatro formas diferentes: sim e não, múltipla escolha, escala Lickert, além de algumas perguntas abertas.

Para checar a consistência dos dados levantados e aprofundar certas questões mais complexas, conduziram-se, também, entrevistas propriamente ditas, com os mesmos executivos, seguindo um roteiro semi-estruturado dos pontos a serem discutidos.

No que concerne ao tratamento dos dados, utilizaram-se métodos quantitativos em estatística descritiva: médias, distribuição de freqüência e desvio-padrão, no caso das respostas às perguntas fechadas do questionário; além de métodos qualitativos em técnicas de análise de conteúdo (Morse, 1994; Weber, 1990), no caso das respostas às perguntas abertas e das entrevistas $^{(1)}$. Partiu-se do pressuposto de que o cruzamento dos resultados conseguidos por diferentes meios permitiria superar limitações inerentes a cada um dos métodos adotados.

\section{Resultados}

\section{Identificação dos GEs Atuantes na Indústria Brasileira de SPBI}

Como resultado da análise dos dados coletados na investigação documental, pertinentes aos escopos e recursos das empresas no setor de SPBI (fins 2001 início 2002), realizada com o auxílio dos construtos de Fahey e Randall (1998) e consistente com a definição de GE, inicialmente, identificaram-se dois GEs no setor em estudo (ver Quadro 2). 


\section{Quadro 2: Grupos Estratégicos Inicialmente Identificados, seus Escopos e Recursos}

\begin{tabular}{|c|c|c|}
\hline Item & $\begin{array}{c}\text { Grupo formado por } \\
\text { Cargill Citrus e Citrovita }\end{array}$ & $\begin{array}{c}\text { Grupo formado por } \\
\text { Guacho Agropecuária e Hildebrand }\end{array}$ \\
\hline Escopo de produto & $\begin{array}{l}\text { Dominação plena do negócio de suco de } \\
\text { laranja, com foco no SLCC para exportação }\end{array}$ & Dominação do SPBI no negócio de suco de laranja \\
\hline Escopo geográfico & $\begin{array}{l}\text { Brasil (alcances variados de acordo com } \\
\text { estruturação distributiva de cada fabricante) }\end{array}$ & $\begin{array}{l}\text { Brasil (alcances variados de acordo com estruturação distributiva de } \\
\text { cada fabricante) }\end{array}$ \\
\hline Escopo de cliente (direto) & Lacticinistas e supermercados & Supermercados e rede de lanchonetes fast food \\
\hline Escopo vertical & $\begin{array}{l}\text { Podem integrar-se verticalmente para trás, } \\
\text { detendo pomares próprios, mas produzindo } \\
\text { abaixo de suas necessidades totais } \\
\text { (consideradas como SLCC }+ \text { SPBI) }\end{array}$ & $\begin{array}{l}\text { Normalmente integram-se verticalmente para trás, produzindo a } \\
\text { própria laranja em quantidade plena (ou quase) para suas } \\
\text { necessidades totais do SPBI }\end{array}$ \\
\hline Escopo de stakeholder & $\begin{array}{l}\text { Governo, Produtores de laranja, Trabalhadores } \\
\text { volantes na agricultura, Profissionais de } \\
\text { assistência técnica na agricultura, Profissionais } \\
\text { na pesquisa científica, Transportadores de } \\
\text { laranja, Produtores de bagaço de cana (caso } \\
\text { apenas da Cargill Citrus), Produtores de } \\
\text { insumos à lavoura de laranja, Produtores de } \\
\text { maquinário para o processamento da laranja, } \\
\text { Acionistas/proprietários da empresa, Clientes } \\
\text { da empresa (exportadores, supermercadistas, } \\
\text { distribuidores), Empregados da empresa, } \\
\text { Consumidores finais }\end{array}$ & $\begin{array}{l}\text { Governo, Produtores de laranja (eventualmente), Trabalhadores } \\
\text { volantes na agricultura, Profissionais de assistência técnica na } \\
\text { agricultura, Profissionais na pesquisa científica, Transportadores de } \\
\text { laranja, Produtores de insumos à lavoura de laranja, Produtores de } \\
\text { maquinário para o processamento da laranja, } \\
\text { Acionistas/proprietários da empresa, Clientes da empresa } \\
\text { (supermercadistas, distribuidores), Empregados da empresa, } \\
\text { Consumidores finais }\end{array}$ \\
\hline Recursos & $\begin{array}{l}\text { Competências geradas a partir de atuação forte } \\
\text { no mercado brasileiro de SLCC para } \\
\text { exportação }\end{array}$ & Competências no SPBI \\
\hline
\end{tabular}

O primeiro GE era formado pelas empresas Citrovita e Cargill Citrus, que competiam na indústria brasileira de SPBI à base de interesse paralelo neste mercado, já que seu negócio principal era o SLCC. Contudo, três fatos aguçaramlhes o interesse no SPBI: sua produção estender-se pelos períodos fora do pico de safra da laranja, a desvalorização havida nas cotações do SLCC e o crescimento do mercado interno do SPBI. No caso específico da Cargill Citrus, a empresa tinha-se pautado, mais do que simplesmente pela venda de produtos, pela cultura do atendimento às necessidades dos clientes/parceiros, no sentido de buscar soluções das quais, eventualmente, estes últimos necessitavam. Assim, sua entrada no mercado do SPBI foi conseqüência do atendimento à necessidade de um parceiro (a Nestlé) que, em 1990, desejava ingressar neste mercado, atraída pelo sucesso da Parmalat.

O segundo GE era constituído por Hildebrand e Guacho Agropecuária, que se introduziram no mercado brasileiro de SPBI, buscando beneficiarem-se ou de algum tipo de convivência anterior com a citricultura ou de familiaridade preexistente com o agronegócio.

Cabe frisar que as empresas do primeiro GE atuavam em dois mercados do suco de laranja, o do SLCC para exportação e o do SPBI para o mercado interno. 
No primeiro, apresentavam comportamento cooperativo expresso em joint ventures, para exploração de terminais no exterior, reduzindo, assim, os investimentos e a capacidade ociosa" (Marino, 2001, p. 46). Com isto, o GE Cargill Citrus-Citrovita também constituía um BE.

Também cabe salientar que, no setor brasileiro de SLCC, embora as empresas sejam oficialmente concorrentes, na prática não se comportam como tais. Conforme Marino (2001), neste setor observa-se um caso clássico de coordenação oligopolista: sua configuração divide-se entre a coordenação tácita e o cartel, sendo esta coordenação facilitada pelo pequeno número de firmas existentes e pela sua elevada concentração espacial.

É importante observar que a pesquisa de campo apontou a existência de três GEs no setor pesquisa, contradizendo o que se obtivera na pesquisa secundária, com base nos insumos que trouxe, relativos aos perfis estratégicos das quatro empresas, a partir dos dados levantados por meio de questionário e validados nas entrevistas no âmbito do estudo de multicasos. Assim, enquanto se confirmou a existência do GE Cargill-Citrovita (doravante chamado de GCC), não se sancionou a existência do GE Guacho-Hildebrand. Em verdade, cada uma destas duas últimas formaria um GE único, conforme os perfis que se seguem.

- Cargill Citrus. Seu negócio principal era o SLCC, segmento onde se destacava como um dos 5 maiores players no país. Em paralelo, apresentava uma atuação consistente no mercado de SPBI: embora a quantificação do volume produzido desta bebida não pudesse ser divulgada, a empresa atendia a um parceiro lacticinista de grande status (Nestlé), a um parceiro supermercadista também de grande status (Carrefour), além de oferecer uma marca própria de SPBI. Suas metas neste mercado eram de ser reconhecida pela excelência tanto do seu produto quanto do tratamento a seus clientes. Seu competidor mais destacado era a Guacho devido à escala de produção; os dois recursos mais importantes eram a escala ou tamanho do negócio e a habilidade para atender às necessidades diferenciadas dos clientes.

- Citrovita. Seu negócio principal também era o SLCC, onde também se destacava como um dos 5 maiores players no Brasil. Até fins de 2001, quando esteve presente no mercado de SPBI, chegou a firmar parcerias com 5 lacticinistas (com destaque para Danone e Leco-Vigor) e 1 supermercado (Carrefour). Sua produção anual chegava a 25 milhões de litros/ano, e suas metas neste mercado eram as mesmas da Cargill Citrus, considerada como seu maior competidor, devido à capacidade ociosa. Os recursos considerados mais importantes eram a habilidade para controlar custos e a integração vertical. Note-se que o motivo alegado pela Citrovita para retirar-se do mercado do 
SPBI foi o baixo retorno em relação ao custo requerido, porquanto a diversificação exigia o desvio de esforços do negócio central - o SLCC, bem como a entrada de novos competidores que poderiam comprometer sua fatia de mercado.

- Guacho Agropecuária/Nova América. O negócio principal do Grupo Nova América era o complexo sucro-alcooleiro, mas sua unidade da Guacho Agropecuária de Santa Cruz do Rio Pardo (SP) era totalmente dedicada ao negócio citrícola, envolvendo desde o plantio da laranja até a distribuição final do SPBI e a exportação do SLCC. Sua meta declarada era de tornar-se líder de vendas. Para tanto, em 2002, ampliara de 4 para 5 suas parcerias com supermercados, expandira o número de marcas próprias de 1 para 3 , passara a fabricar para 4 lacticinistas, e incluíra até mesmo competidores em sua carteira de clientes. O fato de já possuir boa estrutura de distribuição e de penetração no varejo por meio de seus produtos derivados da cana-de-açúcar lhe permitia oferecer também a distribuição do SPBI a seus clientes. Via na Del Valle seu maior competidor, salientando-lhe a capacidade distributiva.

. Hildebrand. A menor empresa pesquisada tinha seu negócio principal no SPBI, que se responsabilizava praticamente pela totalidade de sua produção de suco de laranja. Sua postura competitiva remetia a seus limitados recursos. Estava aberta a novos tipos de negócios com qualquer tipo de parceiro, buscava meios de tornar seu SPBI competitivo em preços (não oferece tampa na embalagem, por exemplo) e utilizava seu pequeno porte como ponto forte em face da clientela, já que lhe garantiria agilidade no atendimento dos pedidos e cuidado na produção de diferenciados em relação aos competidores de maior porte. Por isto mesmo o recurso que entendia ser o mais relevante neste mercado era a habilidade para atender às necessidades diferenciadas dos clientes, e uma de suas metas era ser reconhecida pela excelência do seu produto. Ao informar que seu maior competidor era a Nova América, em virtude da auto-suficiência em fruta, a Hildebrand sinalizava que a disponibilidade própria da laranja era um importante gargalo a seu crescimento no mercado do suco desta fruta; isto porque adquiríla de terceiros implicaria maiores custos, prejudicando sua estratégia de penetração via oferecimento de SPBI com preço final competitivo.

\section{Identificação das Barreiras de Mobilidade no Setor do SPBI}

Considerando-se que as barreiras de mobilidade foram atribuídas aos compromissos de escopo e de recursos das empresas nos GEs, utilizou-se o Quadro 2 para a identificação das barreiras de mobilidade existentes no SPBI para cada uma das empresas dos GEs estudados. Chegou-se, assim, aos resultados elencados a seguir. 
No caso tanto da Citrovita, quanto da Cargill Citrus, conforme pode ser observado no Quadro 2, seu escopo de produto era o SLCC, seu escopo geográfico era o mercado externo, e seu escopo de cliente direto era o importador estrangeiro. Verificou-se que era neste mercado que ambas as empresas concentravam seus recursos e do qual se originaram suas competências centrais, relativas à produção de uma commodity, exportada no sistema $b u l k^{(2)}$. Estes compromissos de escopo constituíram uma barreira à entrada destas empresas no SPBI, porquanto não lhes davam espaço à geração de competências em dois pontos sensíveis no seu mercado: a distribuição no mercado interno (com seus requerimentos de estrutura refrigerada e de capilaridade nos pontos-de-venda) e a detenção de marca conhecida.

No caso da Guacho Agropecuária, sendo o braço citrícola do grupo econômico Nova América, seus compromissos de escopo e de recursos se confundiam com os da empresa-mãe. Assim, se os compromissos originais de escopo e de recursos da Guacho, em termos de produto, eram com a laranja e o SPBI, em termos geográficos eles estavam restritos aos mercados onde a Nova América já colocava seus produtos sucro-alcooleiros e, em termos de cliente, limitados àqueles também já conquistados pela Nova América. Em outras palavras, historicamente não faziam parte dos recursos, nem da Guacho Agropecuária nem da Nova América, a detenção de marca do SPBI, nem uma capilaridade distributiva além das fronteiras alcançadas pelos produtos da Nova América. Portanto, à semelhança do observado na Cargill e na Citrovita, estas lacunas constituíam barreiras de entrada no mercado desta bebida.

Já no caso da Hildebrand, o escopo de seu produto era, originalmente, a produção agrícola, incluindo a de laranja, tendo passado a incluir o SPBI em 1990, conforme o mercado interno se desenvolvia. Com isto, enquanto agroindústria, seus compromissos de escopo e de recursos referiam-se fundamentalmente à produção do SPBI. A empresa também comprometia recursos com a estruturação da distribuição refrigerada, mas estes compromissos não incluíam marca conhecida para a bebida, fato que, à semelhança no observado nas demais empresas, constituía-se em barreira à sua entrada no mercado do SPBI.

Em suma, identificaram-se as seguintes barreiras de mobilidade para a entrada das empresas sob estudo no mercado do SPBI: (1) estruturação para a distribuição refrigerada e detenção de marca conhecida, no caso da Cargill e da Citrosuco; (2) marca conhecida e maior capilaridade na distribuição, no caso da Guacho Agropecuária; (3) marca conhecida e potenciação da capacidade distributiva refrigerada, no caso da Hildebrand. 


\section{Ameaças e Oportunidades ao Grupo Cargill Citrus/Citrovita - GCC pela Ótica Relacional}

A ótica relacional para a análise das ameaças e oportunidades do GCC é uma inovação à perspectiva tradicional do estudo dos GEs. Nesta última, seriam contempladas apenas as implicações antagônicas das cinco forças porterianas: novos entrantes, rivais, fornecedores, compradores e substitutos; e dos fatores macro-ambientais interagentes, estudadas pelo ângulo da geração de oportunidades, ameaças e barreiras de mobilidade aos atores envolvidos, quando aquelas forças são exercidas. Já na análise relacional do caso do GCC - ou seja, aqui enquanto BE - foram avaliadas as implicações estratégicas das suas redes, ao influenciarem a mobilidade intergrupal, no caso especial de empresas que são estruturalmente similares e mais conectadas entre si do que com as demais, e pertencentes ao mesmo GE.

Conforme identificado na investigação documental, o GCC envolveu-se em três tipos principais de redes. (1) Rede 1: A rede que dá origem ao próprio bloco, composta das ligações da Cargill Citrus com a Citrovita e vice-versa. (2) Rede 2: A rede derivada das respectivas alianças com lacticinistas e supermercados no mercado de SPBI. (3) Rede 3: A rede derivada das ligações com as demais empresas produtoras de SLCC. Vale notar que, em um segundo plano, têm-se redes paralelas, também relevantes para o desempenho das empresas do GCC, tais como a rede onde os lacticinistas distribuidores interagem com as cadeias varejistas que revendem o SPBI. Não fazem, porém, parte da pesquisa, por questão de delimitação do seu escopo.

A partir daí podem visualizar-se algumas das principais ameaças e oportunidades ao GCC (ver Quadro 3). As ameaças às empresas aqui consideradas como o grupo GCC e analisadas como constituindo um BE no mercado de SLNC, provêm tanto da importância do mercado de SLCC para a Cargill Citrus e para a Citrovita, porquanto se tratava do negócio principal de ambas, como também do fato de os relacionamentos entre as empresas do GCC e os lacticinistas/supermercadistas (ou seja, da rede maior onde o bloco se encontra) se limitarem a alianças de marketing. A combinação destes dois elementos faz com que os interesses advindos do mercado de SPBI terminem por se subordinar àqueles advindos do SLCC. No caso do relacionamento entre as empresas do GCC e os lacticinistas/ supermercadistas, há uma nítida separação entre os negócios de produção (que cabem às empresas do GCC) e de distribuição (que cabem aos lacticinistas e aos supermercados). 


\section{Quadro 3: Oportunidades e Ameaças ao GCC no Mercado de SPBI - Visão Relacional}

\begin{tabular}{|c|c|c|c|}
\hline $\begin{array}{c}\text { Características da } \\
\text { Estrutura das Redes }\end{array}$ & Indicadores & Oportunidades & Ameaças \\
\hline \multicolumn{4}{|l|}{ 1. Densidade } \\
\hline $\begin{array}{l}\text { 1.1.Na rede entre o GCC } \\
\text { e os lacticinistas/ supermercadistas (Rede 2) }\end{array}$ & $\begin{array}{l}\text { 1.1. Muito baixa : A ligação } \\
\text { dos lacticinistas/ supermercadistas com } \\
\text { o GCC é limitada a situação de } \\
\text { prestação de serviços por parte do } \\
\text { GCC, não chegando a se configurar em } \\
\text { uma rede mas apenas em uma relação } \\
\text { comercial. }\end{array}$ & \multicolumn{2}{|c|}{$\begin{array}{l}\text { 1.1. Relativo desinteresse do } \\
\text { GCC e dos lacticinistas/ supermercadistas em } \\
\text { perpetuar o relacionamento, facultando a entrada de } \\
\text { outros atores como substitutos de qualquer uma das } \\
\text { partes }\end{array}$} \\
\hline $\begin{array}{l}\text { 1.2. Na rede dentro do GCC } \\
\text { (Rede 1), e entre o GCC e as demais empresas } \\
\text { produtoras de SLCC (Rede } 3 \text { ) }\end{array}$ & $\begin{array}{l}\text { 1.2. Alta: A ligação entre as } \\
\text { empresas do GCC é alta devido à } \\
\text { cooperação relativa que impera no } \\
\text { mercado de SLCC; pelo mesmo } \\
\text { motivo, também é alta a ligação do } \\
\text { GCC com as demais produtoras de } \\
\text { SLCC }\end{array}$ & \multicolumn{2}{|c|}{$\begin{array}{l}\text { 1.2. Coordenação oligopolista } \\
\text { no mercado de SLCC traz reflexos positivos no } \\
\text { mercado de SPBI }\end{array}$} \\
\hline 2. Posição (Rede 2) & $\begin{array}{l}\text { 2.1. Centralidade: tanto as empresas } \\
\text { que compōem o GCC como os } \\
\text { respectivos lacticinistas distribuidores/ } \\
\text { supermercadistas ocupam posiçóes } \\
\text { centrais devido ao status de suas } \\
\text { marcas }\end{array}$ & \multicolumn{2}{|c|}{$\begin{array}{l}\text { 2.1.A penetração do SPBI nos pontos-de-venda é } \\
\text { facilitada pela linha de lácteos dos lacticinistas e pela } \\
\text { força de suas marcas; o GCC se beneficia, no SPBI, de } \\
\text { vantagens oriundas do mercado de SLCC }\end{array}$} \\
\hline 3. Centralidade (Rede 2) & $\begin{array}{l}\text { 3. Alta: Devido ao status de suas } \\
\text { marcas, tanto as empresas que } \\
\text { compõem o GCC quanto os lacticinistas } \\
\text { distribuidores/ supermercadistas detêm } \\
\text { alta centralidade, apresentando } \\
\text { conexões com muitos mais parceiros } \\
\text { do que as conexões apresentadas por } \\
\text { rivais menos centrais }\end{array}$ & \multicolumn{2}{|c|}{$\begin{array}{l}\text { 3. Benefícios em todas as etapas de produção e de } \\
\text { distribuição do SPBI, resultando no oferecimento de } \\
\text { produto de elevada qualidade e distribuído de forma } \\
\text { adequada às suas características de perecibilidade }\end{array}$} \\
\hline \multicolumn{4}{|l|}{ 4. Escopo } \\
\hline $\begin{array}{l}\text { 4.1. Na rede entre o GCC e os lacticinistas/ } \\
\text { supermercadistas (Rede 2), e entre os lacticinistas } \\
\text { e os distribuidores varejistas }\end{array}$ & $\begin{array}{l}\text { 4.1. Estreito, pouco e local: o escopo } \\
\text { da rede do GCC com os lacticinistas/ } \\
\text { supermercadistas é limitado, } \\
\text { restringindo-se o grupo a ser mero } \\
\text { prestador de serviço aos distribuidores; } \\
\text { o escopo da rede dos laticinistas } \\
\text { distribuidores com os canais varejistas } \\
\text { é estreito em termos de opçôes, } \\
\text { concentrando-se nos canais } \\
\text { tradicionais, que nem sempre possuem } \\
\text { a capilaridade necessária para } \\
\text { confrontar as bebidas concorrentes ao } \\
\text { SPBI }\end{array}$ & & $\begin{array}{l}\text { 4.1. Relativo desinteresse do GCC em } \\
\text { perpetuar o relacionamento, } \\
\text { facultando a entrada de outros atores } \\
\text { como substitutos no fornecimento de } \\
\text { SPBI aos lacticinistas/ } \\
\text { supermercadistas, e como substitutos } \\
\text { na distribuição às empresas que } \\
\text { compõem o GCC; ausência do SPBI } \\
\text { dos canais alternativos que pudessem } \\
\text { aumentar a capacidade concorrencial } \\
\text { do SPBI }\end{array}$ \\
\hline $\begin{array}{l}\text { 4.2.Na rede dentro do GCC (Rede 1), e entre } \\
\text { o GCC e as demais empresas produtoras de SLCC } \\
\text { (Rede 3) }\end{array}$ & $\begin{array}{l}\text { 4.2. Amplo, variado e global: as redes } \\
\text { onde se situam as empresas do GCC } \\
\text { são caracterizadas por diversos tipos } \\
\text { de colaboraçâo, tanto entre elas } \\
\text { (oriundos do mercado de SLCC) como } \\
\text { com outras empresas produtoras de } \\
\text { SLCC }\end{array}$ & $\begin{array}{l}\text { 4.2. Reflexo dos benefícios em custos/ } \\
\text { competitividade no mercado de SPBI }\end{array}$ & \\
\hline \multicolumn{4}{|l|}{ 5. Padrão, força e natureza das ligações } \\
\hline $\begin{array}{l}\text { 5.1. Na rede entre o GCC e os lacticinistas/ } \\
\text { supermercados (Rede 2) }\end{array}$ & $\begin{array}{l}\text { 5.1. Relativamente fracas, } \\
\text { oportunísticas e não-múltiplas entre o } \\
\text { GCC e os lacticinistas/ } \\
\text { supermercadistas: contratos formais de } \\
\text { fornecimento de SPBI aos lacticinistas } \\
\text { são ligaçães diretas mas que } \\
\text { caracterizam o grupo como mero } \\
\text { prestador de serviço, não havendo } \\
\text { integração dos conhecimentos entre os } \\
\text { lacticinistas e o GCC, nem } \\
\text { compartilhamento de eventuais ganhos } \\
\text { que possam ocorrer na ponta da } \\
\text { distribuição; o SPBI é commodity e } \\
\text { pode ser fornecido por outras } \\
\text { empresas; o core business do GCC é o } \\
\text { SLCC }\end{array}$ & & $\begin{array}{l}\text { 5.1. Ausência de maior solidez nas } \\
\text { alianças, possibilidade de rompimento } \\
\text { fortuito do contrato de fornecimento } \\
\text { do SPBI: baixo interesse do GCC em } \\
\text { permanecer em rede com os } \\
\text { lacticinistas/ supermercadistas }\end{array}$ \\
\hline 5.2. Na rede dentro do GCC (Rede 1) & $\begin{array}{l}\text { 5.2. Fortes, colaborativas e múltiplas } 5 \text {. } \\
\text { entre as empresas que compoomem o } \\
\text { GCC, derivadas da coordenação que } \\
\text { impera entre os fabricantes no mercado } \\
\text { de SLCC }\end{array}$ & Reflexos positivos no mercado de SPBI & \\
\hline
\end{tabular}




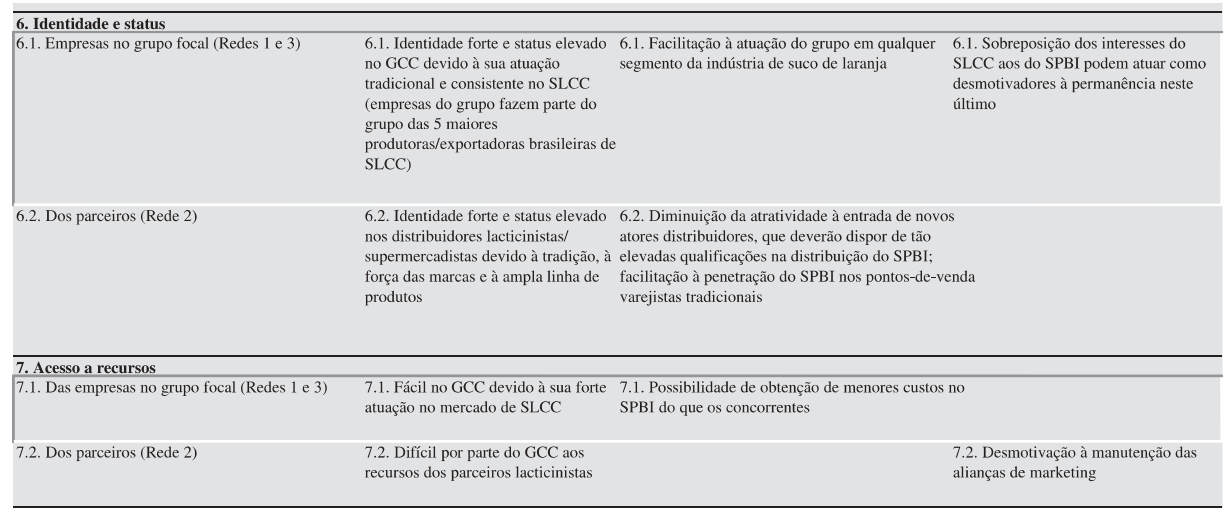

Já pelo lado dos elementos relacionais que favorecem a permanência das empresas do GCC no mercado de SPBI, desestimulando a entrada de concorrentes, eles se apóiam nas vantagens que estas empresas apresentam, enquanto BE, em todos os aspectos relativos à produção da bebida por dois ângulos: a) oriundas das características da rede do próprio bloco (o que se chamou de Rede 1); b) oriundas da rede maior onde o bloco se encontra (o que se chamou de Redes $2 \mathrm{e}$ 3 ). Isto pode ser verificado em termos de densidade (Redes 1 e 3, ponto 1.2. no Quadro 3), posição (Rede 2, ponto 2.1.), centralidade (Rede 2, ponto 3.1.), escopo (Rede 1, ponto 4.2), ligações (Rede 1, ponto 5.2.), identidade e status (Redes 1 e 3, ponto 6.1.), e de acesso a recursos (Redes 1 e 3, ponto 7.1.).

\section{Resultados da Pesquisa no Âmbito das Alianças e Redes de Relacionamento}

Apresentam-se, nesta seção, as descobertas mais relevantes da pesquisa primária sobre as alianças e redes de relacionamento das empresas estudadas.

No caso da Cargill Citrus, a pesquisa revelou que a empresa possuía alianças estratégicas bilaterais com clientes, fornecedores e complementador, abstendose de possuí-las com concorrentes, com substitutos ou com novos entrantes. Não via nestas alianças, nem nas redes daí surgidas, capacidade de mudarem a intensidade da competição na indústria de SPBI, embora as considerasse fundamentais para sua estratégia competitiva neste mercado. Classificava como as mais importantes aquelas firmadas com clientes-chaves. As alianças e redes eram vistas como forma de ter acesso a informações relevantes proporcionadas por novo relacionamento, economia de escala e compartilhamento de recursos/ competências complementares. Em termos das características de estrutura, de composição e de modalidade de seus relacionamentos em redes, a pesquisa chegou aos seguintes resultados: (1) Com clientes-chaves - densidade alta, centralidade 
muito alta, escopo estreito, variedade de recursos média, identidade e status forte/ elevado dos parceiros, acesso fácil e difícil aos recursos dos parceiros, laços diretos e fortes, ligações colaborativas e multilaterais. (2) Com fornecedores chaves - densidade média, centralidade muito alta, escopo estreito, variedade de recursos média, alcance dos recursos nacional, identidade dos parceiros fraca, status dos parceiros elevado e baixo, acesso fácil aos recursos dos parceiros, laços diretos e fortes, ligações colaborativas e multilaterais. (3) Com complementador principal - densidade média, centralidade muito alta, escopo estreito, variedade de recursos média, alcance dos recursos internacional, identidade e status forte/elevado do parceiro, acesso fácil aos recursos do parceiro, laços diretos e fortes, e ligações colaborativas e unilaterais.

No caso da Citrovita, a pesquisa revelou que ela possuía alianças estratégicas bilaterais com clientes, fornecedores e complementador, abstendo-se de possuílas com concorrentes, com substitutos ou com novos entrantes. A empresa via nestas alianças, e nas redes daí surgidas, capacidade de mudar a intensidade da competição na indústria de SPBI, considerando-as fundamentais para sua estratégia competitiva neste mercado. Classificava como as mais importantes aquelas firmadas com clientes-chaves. As alianças e redes eram vistas como forma de ter acesso a informações relevantes proporcionadas por novos relacionamentos, de gerenciar riscos e incertezas e de compartilhar recursos/ competências complementares. Em termos das características de estrutura, de composição e de modalidade de seus relacionamentos em rede, estas foram assim definidas. (1) Com clientes-chaves - densidade alta, centralidade muito alta, escopo amplo, variedade de recursos elevada, alcance dos recursos internacional, laços diretos e fortes, ligações colaborativas e unilaterais, identidade e status forte/elevado dos parceiros, acesso fácil aos recursos dos parceiros. (2) Com fornecedores-chaves - densidade alta, centralidade muito alta, escopo amplo, variedade de recursos elevada, alcance dos recursos nacional, laços diretos e fortes, ligações colaborativas e multilaterais, identidade e status forte/ elevado dos parceiros, acesso fácil aos recursos dos parceiros. (3) Com complementador - densidade alta, centralidade alta, escopo amplo, variedade de recursos média, alcance dos recursos internacional, laços diretos e fortes, ligações colaborativas e unilaterais, identidade e status forte/elevado dos parceiros, acesso fácil aos recursos dos parceiros.

Por sua vez, no caso da Guacho Agropecuária, a pesquisa verificou que a empresa já possuía alianças estratégicas bilaterais com clientes, concorrentes e complementador, abstendo-se de possuí-las com fornecedores, com substitutos ou com novos entrantes. Via, de forma enfática, que estas alianças, e as redes daí surgidas, tinham capacidade para mudar a intensidade da competição na indústria de SPBI, considerando-as, também de forma enfática, como fundamentais 
para sua estratégia competitiva neste mercado. Classificava como as mais importantes aquelas firmadas com clientes-chaves, tendo colocado em segundo lugar na importância as alianças com os concorrentes. As alianças e redes eram vistas como forma de obter economia de escala, de gerenciar riscos e incertezas, e de reduzir os custos de entrada em novos mercados ou segmentos industriais. Em termos das características de estrutura, de composição e de modalidade dos relacionamentos em rede, os resultados permitiram fazer as seguintes inferências. (1) Com clientes chaves - densidade alta, centralidade muito alta, escopo amplo, variedade de recursos elevada, alcance dos recursos internacional, laços diretos, fortes e fracos, ligações oportunistas e unilaterais, identidade e status forte/elevado dos parceiros, acesso difícil aos recursos dos parceiros. (2) Com concorrentes chaves - densidade média, centralidade média, escopo da rede estreito, variedade de recursos baixa, alcance dos recursos nacional, laços diretos e fracos, ligações oportunistas e unilaterais, identidade e status forte/elevado dos parceiros, acesso difícil aos recursos dos parceiros. (3) Com complementador principal - densidade média, centralidade média, escopo da rede amplo, variedade de recursos elevada, alcance dos recursos internacional, laços diretos e fortes, ligações oportunistas e multilaterais, identidade e status forte/elevado dos parceiros, acesso fácil aos recursos dos parceiros.

Com relação à última empresa estudada, a Hildebrand, a pesquisa forneceu evidências de que ela possui alianças estratégicas com todos os tipos de parceiros, até mesmo com concorrentes chaves e substitutos principais. Via, de forma enfática, que estas alianças, e as redes daí surgidas, tinham capacidade para mudar a intensidade da competição na indústria de SPBI, considerando-as como fundamentais para sua estratégia competitiva neste mercado. Classificava como as mais importantes os relacionamentos com clientes-chaves. As alianças e redes eram vistas como forma de ter acesso a informações relevantes proporcionadas por novos relacionamentos, de compartilhar custos, e de reduzir os custos de entrada em novos mercados ou segmentos industriais. Em termos das características de estrutura, de composição e de modalidade, a seguir descrevemse os principais resultados da pesquisa primária: (1) Relacionamentos com clienteschaves - densidade baixa, centralidade média, escopo amplo, variedade de recursos elevada, alcance dos recursos nacional, laços diretos e fortes, ligações colaborativas e multilaterais, identidade e status dos parceiros forte/elevado e fraco/baixo, acesso fácil aos recursos dos parceiros. (2) Com fornecedores chaves - densidade média, centralidade média, escopo amplo, variedade de recursos elevada, alcance dos recursos nacional, laços diretos e fortes, ligações colaborativas e multilaterais, identidade e status dos parceiros forte/elevado, acesso fácil aos recursos dos parceiros. (3) Com concorrentes chaves - densidade baixa, centralidade média, escopo da rede estreito, variedade de recursos baixa, alcance dos recursos nacional, laços diretos e fortes, ligações oportunistas e unilaterais, identidade e status forte/ 
elevado dos parceiros, acesso difícil aos recursos dos parceiros. (4) Com substitutos principais - densidade baixa, centralidade média, escopo da rede amplo, variedade de recursos elevada, alcance dos recursos nacional, laços diretos e fortes, ligações colaborativas e multilaterais, identidade fraca e status baixo dos parceiros, acesso fácil aos recursos dos parceiros. (5) Com complementador principal - densidade média, centralidade média, escopo da rede amplo, variedade de recursos elevada, alcance dos recursos nacional, laços diretos e fortes, ligações oportunistas e unilaterais, identidade e status forte/elevado dos parceiros, acesso fácil aos recursos dos parceiros.

\section{Discussão - Alianças e Redes Estratégicas e Barreiras INTERGRUPAIS}

Com vistas à confirmação de que as redes de relacionamentos estratégicos podem, de fato, constituir meios de superar as barreiras de mobilidade no caso de GEs, precisamente nesta pesquisa do GCC cabe compartilhar primeiro as conclusões da confrontação dos resultados da pesquisa primária com os da secundária a respeito das implicações estratégicas das alianças e redes do GE enfocado. No caso das alianças com fornecedores-chaves (produtores de laranja), estas se revelaram diferenciadas em relação às demais. Os motivos para tanto foram quatro, transcendendo o próprio mercado do SPBI: sem laranja não há suco; as empresas do GCC estavam longe do auto-abastecimento nesta matéria prima; o negócio principal do GCC é o mercado do SLCC (cujo volume de mercado é mais de cinco vezes maior do que o do SPBI, implicando forte dependência das empresas produtoras de suco aos produtores de laranja); e a laranja posta fábrica responde por 72\% do custo de produção do SLCC.

Daí não se estranha que tenha havido quase consenso pleno, entre as empresas do GCC, no que tange às características de modalidade e de composição das redes com estes parceiros, indicando sua relevância para a permanência das empresas do GCC no segmento do SPBI. Ficou claro que, em termos das alianças com os clientes-chaves do GCC (lacticinistas e supermercadistas), estas redes são de grande importância para a permanência deste último no mercado do SPBI, porque a sua densidade e centralidade são ambas muito altas; é forte a identidade destes clientes e seu status é elevado, com opiniões consensuais entre as empresas do grupo.

Por outro lado, as empresas do GCC tenderam a divergir não só no que diz respeito ao escopo da rede com estes clientes, como também em relação ao 
padrão, força e natureza das ligações, e em relação ao acesso a seus recursos. Lançou-se a suposição de que esta diferença de opiniões tinha origem nas próprias características do posicionamento estratégico da empresa do grupo: na medida em que esta se via como mera prestadora de serviços, ela tenderia a ser mais complacente com seus parceiros, aceitando a reticência destes em aprofundar o relacionamento, enquanto uma empresa com atitude mais participativa tenderia a ser mais exigente com seus parceiros, cobrando-lhes também esta atitude engajada. As duas empresas do GCC, contrariamente aos outros dois players analisados, não realizavam parcerias com suas concorrentes no mercado do SPBI. Isto significa que excluíram até mesmo uma à outra neste tipo de ligação, indicando que tal tipo de proximidade não era relevante para a sua permanência neste mercado. Porém não se podiam esquecer, conforme apontado na pesquisa secundária, as sinergias freqüentemente observadas entre os negócios de SLCC e de SPBI, a grande interdependência que existe entre as empresas produtoras de SLCC (Margarido, 1996), e o próprio fato de o setor de SLCC apresentar características de coordenação setorial (Azevedo, 1996).

No caso das redes com o parceiro complementador Tetra Pak, verificou-se que estas eram percebidas de forma muito semelhante entre as empresas do GCC, em aspectos que solidificam o relacionamento: laços diretos e fortes, ligações colaborativas, identidade forte, status elevado, acesso fácil aos recursos, centralidade alta ou muito alta. Por outro lado, as ligações eram vistas como unilaterais, e era considerada apenas média a variedade de recursos proporcionada nesta rede. Aparentemente, tratava-se de parceria que, embora relevante para a permanência do GCC no mercado do SPBI (dada a elevada agregação de valor representada por este tipo de embalagem), sofreria a influência do poder da Tetra Pak, já que esta detinha o monopólio virtual de um tipo de embalagem de amplo uso nos segmentos de lacticínios e de bebidas derivadas de frutas.

Foi na confrontação dos resultados sobre as alianças com supermercados e lacticinistas que a pesquisa indicou claramente que estas habilitaram a Cargill Citrus e a Citrovita a suplantar as barreiras de mobilidade, representadas pelos seus próprios compromissos de escopo e de recursos, para adentrarem o mercado do SPBI por meio de marcas conhecidas (dos supermercados e, principalmente, dos lacticinistas) e da sua sólida estrutura de distribuição refrigerada (dos lacticinistas). Com isto, as empresas do GCC se tornaram um agrupamento no mercado do SPBI, porquanto ali continuaram a apresentar compromissos de escopo e de recursos semelhantes, na medida em que seu foco primário se manteve no mercado do SLCC.

Por outro lado, o fato de serem um BE, ou seja, de desfrutarem de conexões 
mais densas entre si do que com as demais e com a rede total que as integra, não interferiu diretamente nesta capacidade de ultrapassagem das barreiras de mobilidade, porquanto ficou comprovado que a Cargill e a Citrovita não realizam parcerias formais com suas concorrentes.

Para o entendimento deste último ponto cabe lembrar aqui a extensão proposta ao conceito de BE na seção 1 deste artigo. Esta extensão ajuda a explicar por que, apesar de formarem um BE no mercado do SPBI, a Cargill e a Citrovita não realizavam parcerias formais uma com a outra: seu grande interesse não residia neste mercado, e sim no do SLCC. Neste, de fato, observavam-se atitudes comportamentais que remetiam a uma coordenação interna e se traduziam em ações concretas de parcerias (Marino, 2001).

No caso das empresas que não se encontravam em bloco - Guacho e Hildebrand - também se confirmou que as alianças com supermercados e lacticinistas as habilitaram a suplantar as barreiras de mobilidade representadas pelos seus próprios compromissos de escopo e de recursos. No caso da Guacho, as alianças com supermercados e lacticinistas lhe garantiram as marcas conhecidas das quais necessitava para estabelecer-se no mercado do SPBI, assim como maior alcance geográfico e penetrabilidade no varejo. No mercado desta bebida, a Guacho Agropecuária passou a representar, por si só, um agrupamento porquanto seus compromissos de escopo e de recursos lhe eram específicos, diferenciando-a das demais empresas analisadas. No que diz respeito à Hildebrand, ainda que restritas em diversidade em face do observado nas demais empresas analisadas, devido ao seu menor tamanho relativo, as alianças firmadas com uma rede de fast food e com supermercado que, posteriormente passaram a incluir também um lacticinista e um novo entrante, habilitaram a empresa a suplantar as barreiras de mobilidade representadas pelos seus próprios compromissos de escopo e de recursos, garantindo-lhe as marcas conhecidas das quais necessitava para estabelecer-se no mercado do SPBI, assim como a potenciação da capacidade distributiva refrigerada. À semelhança do observado no caso da Guacho Agropecuária, no mercado do SPBI a Hildebrand passou a representar, por si só, um agrupamento, na medida em que seus compromissos de escopo e de recursos lhe eram específicos, diferenciandoa das demais empresas investigadas.

\section{Considerações Finais}

A contribuição singular deste artigo refere-se à indicação de que as redes de 
alianças e outros relacionamentos estratégicos, especialmente as de grupos de empresas estruturalmente similares e mais densamente conectadas entre si, podem levar à releitura do paradigma tradicional na análise de GEs, porquanto capacitam as empresas a adentrarem esses grupos sem o constrangimento tradicionalmente ditado pelas barreiras de mobilidade. De fato, por meio de um estudo de multicasos, a pesquisa ilustrou a observação de Nohria e Garcia-Pont (1991), de que as alianças podem prover a uma empresa situada em um GE a capacidade de ultrapassar as barreiras intergrupais, ao habilitarem-na a adquirir capacitações que não se inserem em seu negócio principal, de forma mais rápida e menos custosa do que por meio do desenvolvimento interno destas capacitações. Além desta confirmação, a pesquisa trouxe vários outros subsídios relevantes, tanto para a tomada de decisão e gestão de empresas em GEs que atuam em alianças e redes estratégicas, quanto para a pesquisa sobre o impacto destas. Estes subsídios são elecados a seguir.

- Dependendo do perfil da empresa, alianças podem ser firmadas até mesmo com atores estratégicos que se pensariam improváveis, caso dos concorrentes (observado na Hildebrand e na Guacho Agropecuária), e até dos substitutos (observado apenas no caso da Hildebrand). Este fenômeno serve como indicador ainda mais contundente da importância das parcerias e alianças para a superação das barreiras de mobilidade intergrupais. Para uma empresa que esteja buscando firmar-se (caso da Hildebrand) ou avançar solidamente (caso da Guacho Agropecuária) neste mercado, os relacionamentos, enquanto necessários à superação das barreiras de mobilidade, são vistos sem preconceitos, sendo tão bons quanto os benefícios imediatos que trazem. $\mathrm{Na}$ medida em que eles provêem a maximização do uso da capacidade instalada, a adição de receitas e a visibilidade da empresa no mercado, enquanto prestadora de serviços a terceiros, não cabem questionamentos éticos a respeito. Ademais, o raciocínio subjacente a estes tipos de relacionamento não raro segue uma lógica baseada na especialização do fornecedor: este pode estar em parceria até mesmo com uma empresa que é seu substituto (por exemplo, de refrigerantes, no caso do produtor de suco de laranja) que lhe adquira a matéria prima (por exemplo, o suco de laranja) para a composição do seu produto final, na medida em que o cliente não desejará desviar recursos do seu negócio principal (por exemplo, fabricação de refrigerantes) para iniciar-se em atividade que o fornecedor de suco já desempenha de forma competitiva.

. Nem sempre a habilitação à aquisição de capacitações alternativas ao negócio principal, que garante às empresas a suplantação das barreiras de mobilidade, provém de parcerias e redes de relacionamento com características típicas de uma situação de ganha-ganha entre os parceiros, conforme parece ser o caso 
indicado pela pesquisa no que tange ao complementador Tetra Pak. Neste caso em especial, a pesquisa mostrou que duas empresas (Cargill e Citrovita) consideravam as suas ligações como colaborativas e unilaterais, com acesso fácil aos recursos do parceiro e que, por outro lado, a Hildebrand e a Guacho Agropecuária consideravam suas ligações como oportunistas, sendo que a Hildebrand ainda as qualificava como unilaterais. Embora não tenha havido problema na transferência dos recursos do complementador às parceiras, a situação singular da Tetra Pak no mercado de embalagens praticamente colocava as empresas de SPBI como suas reféns.

- Ao se referirem aos fatores determinantes na tomada de decisão de buscarem alianças e atuarem em redes estratégicas, nenhuma das empresas respondentes mencionou o acesso ao capital social proporcionado por novos relacionamentos. Em contrapartida, mencionaram-se fatores de fundo econômico imediatista, tais como o acesso a informações relevantes proporcionado por novos relacionamentos, o gerenciamento de riscos e incertezas, a redução de custos de entrada em novos mercados e o compartilhamento de recursos / competências complementares.

Fica, portanto, a impressão de que para as empresas em GEs, no setor em estudo, ainda não está claro se as alianças e redes estratégicas podem prover outra forma de capital, diferente dos capitais técnico e comercial - o capital social - bem como todos os benefícios mais específicos em termos de superar barreiras de mobilidade. Por outro lado, é provável que estas empresas não sejam exceções nem na indústria de suco de laranja, nem em muitas outras indústrias no país.

Portanto recomenda-se replicar o tipo de pesquisa em exame neste artigo sobre GEs pela ótica relacional, não somente em outros setores do agronegócio brasileiro, mas em outras indústrias, complementando as análises estratégicas tradicionais de empresas em GEs com análises relacionais, de modo a contribuir para maior conscientização relacional.

\section{Notas}

\footnotetext{
${ }^{1}$ Para maiores detalhes sobre o protocolo da pesquisa, as estatísticas e o conteúdo das entrevistas, ver Troccoli (2002)

${ }^{2}$ Refere-se a grandes quantidades, comercializadas a granel e com característica homogênea.
} 
PORTER, M.

Competitive strategy: techniques for analyzing industries and competitors. New York: The Free Press, 1980.

SOEKARSONO, T. U.

Integration of strategy and economics: triangulating on agribusiness competitiveness through strategy and economic theories. Urbana, 2001. Thesis (Ph.D.) - University of Illinois at Urbana-Champaign.

TAUHATA, T.

Implicações estratégicas das redes de relacionamento: estudo de caso da Unidade de Minério de Ferro da CVRD. Rio de Janeiro, 2002. Dissertação (Mestrado em Administração) Instituto de Administração e Gerência, Pontifícia Universidade Católica do Rio de Janeiro.
TROCCOLI, I. R.

Gerenciando

grupos

estratégicos: arcabouço para a análise das implicações estratégicas das suas redes de relacionamento, Rio de Janeiro, 2002. Tese (Doutorado em Administração) - Instituto de Administração e Gerência, Pontifícia Universidade Católica do Rio de Janeiro.

TROCCOLI, I. R.;

MACEDO-SOARES, T. D. L. V. A. Gestão de empresas em grupos estratégicos: os blocos de relacionamentos estratégicos. Revista de Administração. No prelo.

YIN, R. K.

Case study research: design and methods. London: Sage Publications, 1994.

WEBER, R. P.

Basic content analysis. London: Sage Publications, 1990. 